\title{
Histopathological changes in the choroid plexus after traumatic brain injury in the rats: a histologic and immunohistochemical study
}

\author{
H. Özevren'1, E. Deveci², M.C. Tuncer ${ }^{3}$ \\ ${ }^{1}$ Department of Neurosurgery, Dicle University, Faculty of Medicine, Diyarbakir, Turkey \\ ${ }^{2}$ Department of Histology and Embryology, Faculty of Medicine, University of Dicle, Diyarbakir, Turkey \\ ${ }^{3}$ Department of Anatomy, Faculty of Medicine, University of Dicle, Diyarbakir, Turkey
}

[Received: 17 January 2018; Accepted: 22 February 2018]

Background: Traumatic brain injury (TBI) is in part associated with the disruption of the blood-brain barrier. In this study, we analysed the histopathological changes in E-cadherin and vascular endothelial growth factor (VEGF) expression after $T B I$ in rats.

Materials and methods: The rats were divided into two groups as the control and the trauma groups. Sprague-Dawley rats were subjected to TBI with a weight-drop device using $300 \mathrm{~g} / 1 \mathrm{~m}$ weight-height impact. After 5 days of TBI, blood samples were taken under ketamine hydroxide anaesthesia and biochemical analyses were performed. The control and trauma groups were compared in terms of biochemical values.

Results: There was no change in glutathione (GSH) levels and blood-brain barrier permeability. However, malondialdehyde (MDA) and myeloperoxidase (MPO) activity levels increased in the trauma group. In the histopathological examination, choroid plexus in the lateral ventricle, near the pia mater membrane, was removed. In the traumatic group, some of epithelial cells were hyperplasic. Some of them were peeled off the apical surface and had local degeneration.

Conclusions: In addition, we observed congestion in capillary vessels and mononuclear cell infiltration around the vessels. After TBI, the increase in VEGF levels, vascular permeability, and interaction with VEGF receptors in endothelial cells lead to oedema of the vessel wall. On the other hand, E-cadherin expression decreased in the tight-junction structures between epithelial cells and basal membrane, resulting in an increase in cerebrospinal fluid in the intervillous area. (Folia Morphol 2018; 77, 4: 642-648)

Key words: traumatic brain injury, choroid plexus, vascular endothelial growth factor (VEGF), E-cadherin, proliferating cell nuclear antigen (PCNA)

\section{INTRODUCTION}

Traumatic brain injury (TBI) is common and a major cause of morbidity and mortality worldwide. TBI is accompanied by a biphasic opening of the bloodbrain barrier to macromolecules and by an early and delayed increase in brain water content. However, the molecular and cellular mechanisms underlying these phenomena have not been fully understood. TBI is an injury to the brain caused by a blow or jolt to the head from blunt or penetrating trauma. The injury that occurs at the moment of impact is known as the primary injury. Primary injuries can involve a specific

Address for correspondence: Prof. M.C. Tuncer, PhD, Department of Anatomy, Faculty of Medicine, Dicle University, Diyarbakır, Turkey, tel: +90 412 2488001, ext. 4539 (faculty room), +90 5322744926 (mobile phone), e-mail: drcudi@hotmail.com 
lobe of the brain or the entire brain. Sometimes, the skull may be fractured, but not always. During the impact of an accident, the brain crashes back and forth inside the skull causing bruising, bleeding, and tearing of nerve fibres. In addition, TBI is suspected to contribute to a variety of chronic degenerative processes such as chronic traumatic encephalopathy, Alzheimer disease, and Parkinson disease [33]. TBI is a nondegenerative, noncongenital insult to the brain from an external mechanical force, possibly leading to permanent or temporary impairment of cognitive, physical, and psychosocial functions, with an associated diminished or altered state of consciousness. The definition of TBI has not been consistent and tends to vary according to specialties and circumstances. Often, the term brain injury is used synonymously with head injury, which may not be associated with neurologic deficits. The definition also has been problematic with variations in inclusion criteria. Symptoms of a TBI can be mild, moderate or severe, depending on the extent of damage to the brain. Mild cases may result in a brief change in mental state or consciousness, while severe cases may result in extended periods of unconsciousness, coma or even death [15, 31].

In brain injuries and infections, leukocytes accumulate in the cerebrospinal fluid (CSF) by passing through the choroid plexus. And, severe disruptions occur in the choroid plexus-CSF nexus that destabilise the nearby hippocampal and subventricular neurogenic regions. Following invasive and non-invasive injuries to cortex, several adverse sequelae harm the brain interior. Recovery from TBI is facilitated by upregulated choroidal/ependymal growth factors and neurotrophins, and their secretion into ventricular CSF. There, by an endocrine-like mechanism, CSF bulk flow convects the neuropeptides to target cells in injured cortex for aiding repair processes; and to neurogenic niches for enhancing conversion of stem cells to new neurons.

Histologically, the choroid plexus is a highly vascularised villous structure, covered with a single layer of cuboidal epithelial cells. It is present in all four ventricles of the brain and plays an important and probably major role in the production of CSF. The choroid epithelium is sealed by continuous apical bands of tight junctions, and the capillaries are unusually wide, thin-walled, and fenestrated. The structure of the secretory cells resembles that found in other well-known fluid-transporting epithelia, i.e., they are supplied with various membrane elaborations such as apical microvilli, basal and basolateral infoldings, and interdigitating processes, as well as an abundance of mitochondria [36]. Choroid plexus epithelial cells constitutively express adhesion molecules such as vascular cell adhesion molecule-1, intercellular adhesion molecule-1, P-selectin, and E-cadherin on their surfaces $[6,17,25,35,39,41]$, which help to retain the leukocytes following their exit from the vasculature. Normal adult choroid plexus strongly expresses E-cadherin as adhesion molecules. E-cadherin is found mainly in the epithelia, where it promotes tight cellcell associations known as adherens junctions [6, 37]. The key role of E-cadherin in progression of epithelial tumours is well established. E-cadherin belongs to the cadherin family, which are calcium-dependent transmembrane glycoproteins involved in cell-to-cell adhesion by homophilic interaction between their extracellular domains of two adjacent cells $[12,14,30]$.

Proliferating cell nuclear antigen (PCNA) is a 36-kd DNA polymerase delta auxiliary protein that complexes with cyclin $D$ and cyclin-dependent kinases, involved in the proliferation of neoplastic as well as non-neoplastic cells, and it is specifically expressed in proliferating cell nuclei. This specific antibody recognises PCNA protein, which is at the maximum level in the late $\mathrm{G} 1$ and $S$ phase of proliferating cells [8]. The role of vascular endothelial growth factor (VEGF) in developmental and pathological angiogenesis is well established. Similarly, although transforming growth factor (TGF-b) is involved in angiogenesis, presumably by mediating capillary stability, its involvement in quiescent vasculature is virtually uninvestigated. Growth factors such as VEGF and TGF-b are known to be involved in the maintenance of the choroid plexus. VEGF the vasculature of the choroid plexus and has a role in the permeability of the blood vessels. These factors may also be distributed through the CSF into the brain parenchyma to act on other cells. VEGF and TGF-b may also act on the ependymal cells, which form a metabolic barrier between the brain parenchyma and the CSF [21].

In this study, structural changes in the cell-cell junction structure of choroid plexus, cell apoptosis and vascular angiogenesis were examined histopathologically and immunohistochemically after traumatic brain injury

\section{MATERIALS AND METHODS}

Animals and experimental design

The investigation was conducted in accordance with the Guide for the Care and Use of Laboratory 
Animals published by United States National Institutes of Health (NIH Publication no. 85-23, revised 1996). All procedures performed in this experiment were approved by the Ethics Committee for the Treatment of Experimental Animals (Faculty of Medicine, University of Dicle, Turkey). Male Sprague-Dawley rats (300$-350 \mathrm{~g}$ ) were maintained under $23 \pm 2^{\circ} \mathrm{C}$ and $12 \mathrm{~h}$ light/dark cycles with ad libitum access to standard pelleted food and water. The rats were divided into two groups as trauma and control. A rectal probe was inserted, and the animals were positioned on a heating pad that maintained the body temperature at $37^{\circ} \mathrm{C}$. The widely used diffuse brain injury model described by Marmarou et al. [22] was used. Briefly, a trauma device which works by dropping a constant weight from a specific height through a tube was used. A weight of $300 \mathrm{~g}$ was dropped from a $1 \mathrm{~m}$ height, which can induce mild trauma, as shown by Ucar et al. [38]. Each group consisted of 16 animals (control and trauma group). All rats at the end of experiment were healthy and no difference in food/ /water consumption and body weight gain between experimental and control rats were observed. After 5 days, all animals were sacrificed by an intraperitoneal injection of $5 \mathrm{mg} / \mathrm{kg}$ xylazine $\mathrm{HCl}$ (Rompun, Bayer HealthCare AG, Germany) and $40 \mathrm{mg} / \mathrm{kg}$ ketamine $\mathrm{HCl}$ (Ketalar, Pfizer Inc, USA). After TBI, blood samples were taken from the animals and analysed with various biochemical markers. Then, choroid plexus in lateral ventricles were rapidly removed. For the histological examination, choroid plexus tissues were fixed in $10 \%$ formaldehyde solution, post-fixed in $70 \%$ alcohol, and embedded in paraffin wax. The sections were stained with haematoxylin-eosin.

\section{Malondialdehyde and glutathione assays}

Tissue samples were homogenised with ice-cold $150 \mathrm{mM} \mathrm{KCl}$ for the determination of malondialdehyde (MDA) and glutathione (GSH) levels. The MDA levels were assayed for products of lipid peroxidation, and the results are expressed as nmol MDA/g tissue [34]. Glutathion was determined by the spectrophotometric method, which was based on the use of Ellman's reagent, and the results are expressed as $\mu \mathrm{mol} \mathrm{GSH} / \mathrm{g}$ tissue [27].

\section{Tissue myeloperoxidase activity}

Myeloperoxidase (MPO) activity in tissues was measured by a procedure similar to that described by Hillegas et al. [11]. MPO is expressed as U/g tissue.

\section{Evans blue assay for blood-brain barrier permeability}

To evaluate the blood-brain barrier integrity, Evans blue dye was used as a marker of albumin extravasation [10]. Evans blue was expressed as $\mu \mathrm{g} / \mathrm{mg}$ of brain tissue against a standard curve

\section{Immunohistochemical technique}

Formaldehyde-fixed tissue was embedded in paraffin wax for further immunohistochemical examination. Sections were deparaffinised in absolute alcohol. The antigen retrieval process was performed twice in citrate buffer solution ( $\mathrm{pH} \mathrm{6.0),} \mathrm{first} \mathrm{for} 7 \mathrm{~min}$, and second for $5 \mathrm{~min}$, boiled in a microwave oven at $700 \mathrm{~W}$. They were allowed to cool to room temperature for $30 \mathrm{~min}$ and washed twice in distilled water for $5 \mathrm{~min}$. Endogenous peroxidase activity was blocked in $0.1 \%$ hydrogen peroxide for $20 \mathrm{~min}$. Ultra $\mathrm{V}$ block (Cat. No. 85-9043, Invitrogen, Carlsbad, California, USA) was applied for 10 min prior to the application of primary antibodies E-Cadherin antibody 1:100 (Cat. No. MA5-12023, Invitrogen), Vascular-Endothelial Factor (VEGF) antibody (1:100) (Cat. No. PA3-067, Invitrogen). Secondary antibody (Cat. No. 85-9043, Invitrogen) was applied for $20 \mathrm{~min}$. Slides were then exposed to streptavidin-peroxidase for $20 \mathrm{~min}$. Chromogen diaminobenzidine (DAB, Cat. No. 34002, Invitrogen) was used. Control slides were prepared as mentioned above, but omitting the primary antibodies. After counterstaining with Haematoxylin and washing in tap water for $8 \mathrm{~min}$ and in distilled water for $10 \mathrm{~min}$. Then, sections were examined in light microscope.

\section{Statistical analysis}

Statistical analysis was carried out using GraphPad Prism 4.0 software (GraphPad Software, 2003, San Diego, CA, USA). All data are presented as mean \pm standard deviation. Groups of data were compared with an analysis of variance (ANOVA) followed by Tukey's multiple comparison tests. Values of $p<0.05$ were considered as significant.

\section{RESULTS}

When the tissue MPO activities of the control group were compared with that of the trauma group, a statistically significant difference was observed ( $p<0.01$ ); these data showed that after TBI, tissue MPO activity was increased. A significant decrease was observed in trauma group after TBI when compared with control 
Table 1. Statistical analysis of biochemical parameters in the control and trauma groups

\begin{tabular}{lcc}
\hline & Control & Trauma \\
\hline Malondialdehyde $[\mathrm{nmol} / \mathrm{g}]$ & $34.96 \pm 2.945$ & $53.80 \pm 7.810^{* * *}$ \\
Glutathione $[\mu \mathrm{mol} / \mathrm{g}]$ & $1.524 \pm 0.183$ & $0.980 \pm 0.136^{* * *}$ \\
Myeloperoxidase $[\mathrm{U} / \mathrm{g}]$ & $5.894 \pm 0.994$ & $7.322 \pm 0.714^{* *}$ \\
Blood-brain barrier permeability & $2.077 \pm 0.217$ & $3.679 \pm 0.582^{* * *}$ \\
{$[\mathrm{mg} / \mathrm{g}]$} & & \\
\hline
\end{tabular}

Values are represented as mean \pm standard deviation; ${ }^{* *} p<0.01$, versus control; ${ }^{* * *} p<0.001$, versus control

$(p<0.001)$. There were no significant differences between the control and trauma groups in terms of GSH $(p=0.591)$. And also, there were no significant differences between the control and trauma groups in terms of blood-brain barrier permeability (Table 1).

In the control group, epithelial cells of choroid plexus sitting on the membrane were regular and formed protrusions towards the apical surface. Structures of capillaries from pia mater were normal (Fig. 1A). In the group with TBI, some of epithelial cells were hyperplasic, some of were with local degeneration with peeled off from apical surface. Dilation and congestion in capillary vessels, mononuclear cell infiltration around the vessels, and de-squamous cells in inter-villous areas were observed (Fig. 1B). VEGF expression was positively observed in the cells of the ependymal cells of the rat choroid plexus section in the control group, while weak VEGF expression was observed in capillary endothelial cells (Fig. 1C). In the trauma group, an increase in VEGF expression was observed along the choroidal membrane and in the ependymal cells, whereas VEGF expression was also observed in the capillary vascular endothelial cells as well as inflammatory cells (Fig. 1D). The increase in VEGF expression after traumatic injury suggests it may induce angiogenetic effect, especially in the vessels, to affect cellular permeability. In ependymal cells of the control group, PCNA expression was observed negative in the nuclei of vascular endothelial cells (Fig. 2A). After TBI, PCNA expression was positively observed in some of the nuclei of endothelial cells and ependymal cells (Fig. 2B). In the control group, E-cadherin expression was positive in the epithelial cell-membrane areas and in cell-cell junctions (Fig. 2C). In the trauma group, an increase in accumulated secretion was observed in inter-villous areas, while E-cadherin expression was reduced in some epithelial cell-membrane and in cell-cell junction areas (Fig. 2D).

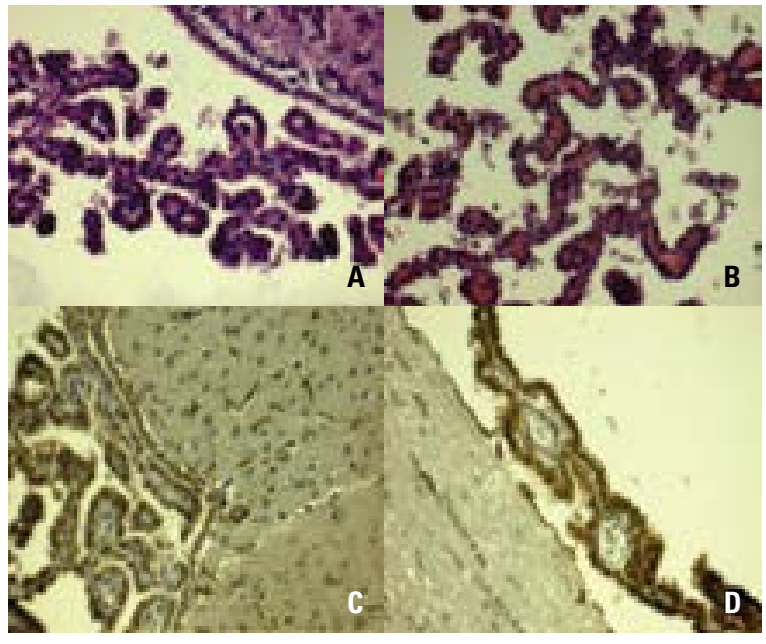

Figure 1. A. Control group. Normal appearance of regular cells and vascular structures in villous processes of choroid plexus, haematoxylin-eosin (HE) staining; bar $100 \mu \mathrm{m}$; B. Trauma group. Hyperplasia and degeneration in some epithelial cells (arrow), dilation and congestion in capillary vessels, mononuclear cell infiltration around the vessels, HE staining; bar $100 \mu \mathrm{m}$; C. Control group. Weak vascular endothelial growth factor (VEGF) expression in capillary endothelial cells, VEGF immunostaining; bar $100 \mu \mathrm{m}$; D. Trauma group. An increase in VEGF expression along the choroidal membrane and in the ependymal cells (arrow), VEGF immunostaining; bar $100 \mu \mathrm{m}$.

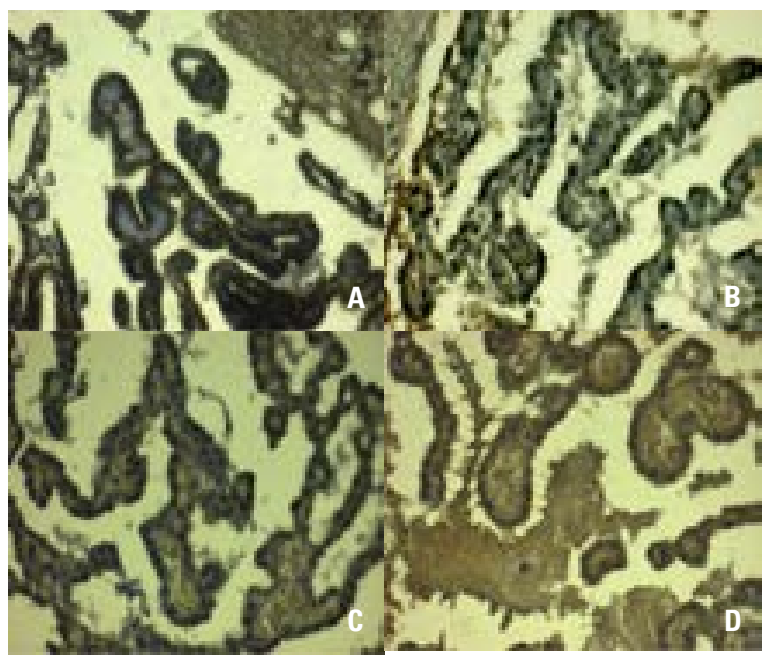

Figure 2. A. Control group. Negative proliferating cell nuclear antigen (PCNA) expression in the nuclei of vascular endothelial cells, PCNA immunostaining and haematoxylin stain; bar $100 \mu \mathrm{m}$; C. Trauma group. PCNA positive expression in some of the nuclei of ependymal and endothelial cells following traumatic brain injury (arrow), PCNA immunostaining and haematoxylin staining; bar $100 \mu \mathrm{m}$; C. Control group. Positive E-cadherin expression in the epithelial cell-membrane areas and in cell-cell junctions, E-cadherin immunostaining; bar $100 \mu \mathrm{m}$; D. Trauma group. Weak E-cadherin expression in some epithelial cell-membrane and in cell-cell junction areas (arrow), E-cadherin immunostaining; bar $100 \mu \mathrm{m}$. 


\section{DISCUSSION}

Traumatic brain injury is an injury that affects not only brain tissue but other functional organs. Previous studies have shown that a variety of pathological factors, such as oxidative stress, the inflammatory response and apoptosis, are involved in secondary brain injury after TBI. Özevren et al. [26] found enlarged blood vessels, bleeding and swelling after traumatic injury in the brain. In addition, nuclei of the neurons were dissociated and vacuolar degeneration was observed. Furthermore, early interventions to reduce the level of oxidative stress and the extent of the inflammatory response can significantly reduce the extent of TBI [9]. TBI often promotes disruption of blood-brain barrier integrity and the neurovascular unit, which can result in vascular leakage, oedema, haemorrhage, and hypoxia. Other pathologic mechanisms include cell death within the meninges and brain parenchyma, stretching and tearing of axonal fibres, and disruptions at the junctions between white and grey matter, stemming from rotational forces that cause shearing injuries [1].

The brain requires a constant supply of oxygen and nutrients for its proper functioning and is extremely vulnerable to hypoxia (reduced supply of oxygen), ischaemia (reduced supply of blood), and hypoxia-ischaemia (a condition wherein there is reduced supply of both blood and oxygen). Following hypoxic or hypoxic-ischaemic insult, some choroid plexus epithelial cells were swollen and filled with closely packed vacuoles indicative of functional impairment. In hypoxic conditions, choroid plexus epithelial cells showed massive accumulation of glycogen and the extrusion of cytoplasmic fragments from the apical cell surfaces into the ventricular lumen, suggesting altered production of CSF [32]. Indeed, following ischaemic insult, evidence of cell death was reported in the choroid plexus [28]. The cell death observed in the choroid plexus is suggested to favour increased permeability at the blood-cerebrospinal fluid barrier, providing access to circulating cytokines, excitatory amino acids, and calcium to the CSF $[7,13,24]$. The cell death in the choroid plexus could also lead to reduced secretion of trophic factors, which could further account for the brain damage [5]. Besides the choroid plexus, structural alterations were observed in ependymal cells, and this would render them permeable to large cytotoxic molecules that had gained access to the CSF from the blood through the disrupted blood-cerebrospinal fluid barrier. These cytotoxic molecules might exacerbate the injury by affecting periventricular brain tissue $[2,29]$.

Several studies indicated that a non-tissue-specific expression of $\mathrm{N}$-cadherin in tumours plays a crucial role in cell migration, invasion, and metastasis, as part of the epithelial-to-mesenchymal transition [40]. E-cadherin expression might facilitate the stabilisation of tumour metastases in a new environment in order to re-establish tissue architecture [3]. The choroid plexus is involved in protecting the central nervous system against cell-membrane barriers, inflammatory cells, pathogens and toxins. Tight junctions between the apical parts of the choroid plexus epithelial cells are necessary for tight junctions and adhesive junctions. After TBI, E-cadherin expression shows a decrease in the cell-cell junction areas. However, the openings in the intercellular space expands and the cerebrospinal fluid spreads over a large area.

The choroid plexus shows high levels of VEGF [42], and its expression has been located on the epithelial cells $[20,23,32,42]$. The effect of elevated VEGF levels in CSF has not been reported, although it is known that elevated VEGF levels in the brain increase the vascular permeability due to the effect of VEGF on endothelial cell junctions and fenestrations in endothelial cells. In hypoxic conditions, the ependymal cells covering the ventricles are enlarged and vacuolated, which is thought to cause CSF to cause extravasation and oedema in the peripheral brain tissue [16]. Krum and Khaibullina [18] showed that inhibition of VEGF signals, including VEGF receptor-1, decreased the numbers of reactive astrocytes and prevented glial scar formation in TBI models. After TBI, the increase in VEGF levels, vascular permeability, and interaction with VEGF receptors in endothelial cells lead to the formation of oedema and oedema in the resulting vessel wall. A critical mechanism in TBI pathophysiology is the activation of astrocytic proliferation which eventually leads to the formation of a glial scar [4, 18]. After TBI, many astrocytes migrated to the wound area and became active rapidly. Studies have shown that PCNA expression is clearly elevated and that many glial fibrillary acidic protein positive cells express PCNA on day 3 post-TBI [19]. In this study, we observed that PCNA positive expression in some of the nuclei of ependymal and endothelial cells following TBI results in increased desquamation in cells, inflammatory cell condensation, deterioration of cell nucleus structure and apoptotic changes. After $\mathrm{TBI}$, tight junctions in the apical surface of cubic cells 
complexes were deteriorated. Since intercellular adherent junctions were weakened, there were changes in cell-cell junctions. When epithelial cells and vascular endothelial cells with their basal membranes are examined in terms of the cell-to-cell reaction, interactions between cells were disrupted. And, it was seen that decreased expression of E-cadherin expression caused increased secretion with alteration of membrane structure.

\section{CONCLUSIONS}

In conclusion, it is thought that the fluidity of the cerebrospinal fluid may be affected by factors: (i) impairment of active transport caused by E-cadherin depletion between cellular junctions of degenerated cells in choroid plexus, (ii) the occupation of apoptotic cells into the intervillous area, (iii) the increase in VEGF proteins in the vascular endothelial cells, (iv) the induction of angiogenic effect after traumatic brain injury.

\section{REFERENCES}

1. Blennow K, Hardy J, Zetterberg $H$. The neuropathology and neurobiology of traumatic brain injury. Neuron. 2012; 76(5): 886-899, doi:10.1016/j.neuron.2012.11.021, indexed in Pubmed: 23217738.

2. Brightman MW, Reese TS. Junctions between intimately apposed cell membranes in the vertebrate brain. J Cell Biol. 1969; 40(3): 648-677, indexed in Pubmed: 5765759.

3. Brunetti B, Sarli G, Preziosi R, et al. E-cadherin expression in canine mammary carcinomas with regional lymph node metastases. J Vet Med A Physiol Pathol Clin Med. 2003; 50(10): 496-500, indexed in Pubmed: 15157016.

4. Busch SA, Silver J. The role of extracellular matrix in CNS regeneration. Curr Opin Neurobiol. 2007; 17(1): 120-127, doi: 10.1016/j.conb.2006.09.004, indexed in Pubmed: 17223033.

5. Chodobski A, Szmydynger-Chodobska J. Choroid plexus: target for polypeptides and site of their synthesis. Microsc Res Tech. 2001; 52(1): 65-82, doi:10.1002/10970029(20010101)52:1<65::AID-JEMT9>3.0.CO;2-4, indexed in Pubmed: 11135450.

6. Figarella-Branger $\mathrm{D}$, Lepidi $\mathrm{H}$, Poncet $\mathrm{C}$, et al. Differential expression of cell adhesion molecules (CAM), neural CAM and epithelial cadherin in ependymomas and choroid plexus tumors. Acta Neuropathol. 1995; 89(3): 248-257, indexed in Pubmed: 7754745.

7. Garabedian BV, Lemaigre-Dubreuil Y, Mariani J. Central origin of IL-1 beta produced during peripheral inflammation: role of meninges. Brain Res Mol Brain Res. 2000; 75(2): 259-263, indexed in Pubmed: 10686346.

8. Georgescu CV, Săftoiu A, Georgescu CC, et al. Correlations of proliferation markers, p53 expression and histological findings in colorectal carcinoma. J Gastrointestin Liver Dis. 2007; 16(2): 133-139, indexed in Pubmed: 17592558.

9. Gyoneva S, Ransohoff RM. Inflammatory reaction after traumatic brain injury: therapeutic potential of targeting cell-cell communication by chemokines. Trends
Pharmacol Sci. 2015; 36(7): 471-480, doi: 10.1016/j. tips.2015.04.003, indexed in Pubmed: 25979813.

10. Hakan T, Toklu HZ, Biber N, et al. Effect of COX-2 inhibitor meloxicam against traumatic brain injury-induced biochemical, histopathological changes and blood-brain barrier permeability. Neurol Res. 2010; 32(6): 629-635, doi: 10.1179/016164109X12464612122731, indexed in Pubmed: 19660237.

11. Hillegass LM, Griswold DE, Brickson B, et al. Assessment of myeloperoxidase activity in whole rat kidney. J Pharmacol Methods. 1990; 24(4): 285-295, indexed in Pubmed: 1963456.

12. Hirohashi S, Kanai Y. Cell adhesion system and human cancer morphogenesis. Cancer Sci. 2003; 94(7): 575-581, indexed in Pubmed: 12841864.

13. Ikeda J, Mies G, Nowak TS, et al. Evidence for increased calcium influx across the choroid plexus following brief ischemia of gerbil brain. Neurosci Lett. 1992; 142(2): 257-259, indexed in Pubmed: 1454224.

14. Jeanes A, Gottardi CJ, Yap AS. Cadherins and cancer: how does cadherin dysfunction promote tumor progression? Oncogene. 2008; 27(55): 6920-6929, doi: 10.1038/ onc.2008.343, indexed in Pubmed: 19029934.

15. Johanson CE, Miller M, Stopa $E$, et al. Disruption of the choroid plexus-CSF-ependymal wall nexus in CNS injury and aging models: Rescue by i.c.v. peptides. In 7th Congress of the Global College of Neuroprotection and Neuroregeneration, Stockholm, Sweden. 2010: 47.

16. Kaur C, Sivakumar V, Ling EA. Melatonin protects periventricular white matter from damage due to hypoxia. J Pineal Res. 2010; 48(3): 185-193, doi:10.1111/j.1600079X.2009.00740.x, indexed in Pubmed: 20136703.

17. Kleine TO, Benes L. Immune surveillance of the human central nervous system (CNS): different migration pathways of immune cells through the blood-brain barrier and blood-cerebrospinal fluid barrier in healthy persons. Cytometry A. 2006; 69(3): 147-151, doi: 10.1002/cyto.a.20225, indexed in Pubmed: 16479603.

18. Krum JM, Khaibullina A. Inhibition of endogenous VEGF impedes revascularization and astroglial proliferation: roles for VEGF in brain repair. Exp Neurol. 2003; 181(2): 241-257, doi: 10.3201/eid0906.020485, indexed in Pubmed: 12781997.

19. Liu $Y$, Wang $Y$, Cheng $C$, et al. A relationship between p27(kip1) and Skp2 after adult brain injury: implications for glial proliferation. J Neurotrauma. 2010; 27(2): 361-371, doi: 10.1089/neu.2008.0581, indexed in Pubmed: 19852587.

20. Maharaj ASR, Saint-Geniez M, Maldonado AE, et al. Vascular endothelial growth factor localization in the adult. Am J Pathol. 2006; 168(2): 639-648, doi: 10.2353/ ajpath.2006.050834, indexed in Pubmed: 16436677.

21. Maharaj ASR, Walshe TE, Saint-Geniez M, et al. VEGF and TGF-beta are required for the maintenance of the choroid plexus and ependyma. J Exp Med. 2008; 205(2): 491-501, doi: 10.1084/jem.20072041, indexed in Pubmed: 18268040.

22. Marmarou A, Foda MA, van den Brink W, et al. A new model of diffuse brain injury in rats. Part I: Pathophysiology and biomechanics. J Neurosurg. 1994; 80(2): 291-300, doi: 10.3171/ jns.1994.80.2.0291, indexed in Pubmed: 8283269.

23. Marti HH, Risau W. Systemic hypoxia changes the organ-specific distribution of vascular endothelial growth 
factor and its receptors. Proc Natl Acad Sci USA. 1998; 95(26): 15809-15814, indexed in Pubmed: 9861052.

24. Nagahiro S, Goto S, Korematsu K, et al. Disruption of the blood-cerebrospinal fluid barrier by transient cerebral ischemia. Brain Res. 1994; 633(1-2): 305-311, indexed in Pubmed: 8137165.

25. Nathanson JA, Chun LL. Immunological function of the blood-cerebrospinal fluid barrier. Proc Natl Acad Sci USA. 1989; 86(5): 1684-1688, indexed in Pubmed: 2784211.

26. Özevren H, Sevgi I, Deveci E, et al. Neuroprotective effects of potentilla fulgens on traumatic brain injury in rats. Anal Quant Cytol Histol. 2017; 39: 35-45.

27. Preston GW, Phillips DH. Quantification of a peptide standard using the intrinsic fluorescence of tyrosine. Anal Bioanal Chem. 2016; 408(9): 2187-2193, doi: 10.1007/ s00216-016-9334-1, indexed in Pubmed: 26879647.

28. Pulsinelli WA, Brierley JB, Plum F. Temporal profile of neuronal damage in a model of transient forebrain ischemia. Ann Neurol. 1982; 11(5): 491-498, doi: 10.1002/ ana.410110509, indexed in Pubmed: 7103425.

29. Rothstein RP, Levison SW. Damage to the choroid plexus, ependyma and subependyma as a consequence of perinatal hypoxia/ischemia. Dev Neurosci. 2002; 24(5): 426-436, doi: 10.1159/000069052, indexed in Pubmed: 12640182.

30. Schmalhofer O, Brabletz S, Brabletz T. E-cadherin, beta-catenin, and ZEB1 in malignant progression of cancer. Cancer Metastasis Rev. 2009; 28(1-2): 151-166, doi: 10.1007/ s10555-008-9179-y, indexed in Pubmed: 19153669.

31. Sharma HS, Zimmermann-Meinzingen S, Johanson CE. Cerebrolysin reduces blood-cerebrospinal fluid barrier permeability change, brain pathology, and functional deficits following traumatic brain injury in the rat. Ann NY Acad Sci. 2010; 1199: 125-137, doi: 10.1111/j.17496632.2009.05329.x, indexed in Pubmed: 20633118.

32. Sivakumar V, Lu J, Ling EA, et al. Vascular endothelial growth factor and nitric oxide production in response to hypoxia in the choroid plexus in neonatal brain. Brain Pathol. 2008; 18(1): 71-85, doi: 10.1111/j.17503639.2007.00104.x, indexed in Pubmed: 17924979.

33. Smith DH, Johnson VE, Stewart W. Chronic neuropathologies of single and repetitive TBI: substrates of dementia?
Nat Rev Neurol. 2013; 9(4): 211-221, doi: 10.1038/nrneurol.2013.29, indexed in Pubmed: 23458973.

34. Sohrab G, Angoorani P, Tohidi M, et al. Pomegranate (Punicagranatum) juice decreases lipid peroxidation, but has no effect on plasma advanced glycated end-products in adults with type 2 diabetes: a randomized double-blind clinical trial. Food Nutr Res. 2015; 59: 28551, indexed in Pubmed:26355954.

35. Steffen BJ, Breier G, Butcher EC, et al. ICAM-1, VCAM-1, and MAdCAM-1 are expressed on choroid plexus epithelium but not endothelium and mediate binding of lymphocytes in vitro. Am J Pathol. 1996; 148(6): 1819-1838, indexed in Pubmed: 8669469.

36. Strazielle N, Ghersi-Egea JF. Choroid plexus in the central nervous system: biology and physiopathology. J Neuropathol Exp Neurol. 2000; 59(7): 561-574, indexed in Pubmed: 10901227.

37. Takeichi M. Cadherin cell adhesion receptors as a morphogenetic regulator. Science. 1991; 251(5000): 1451-1455, indexed in Pubmed: 2006419.

38. Ucar T, Tanriover G, Gurer I, et al. Modified experimental mild traumatic brain injury model. J Trauma. 2006; 60(3): 558-565, doi:10.1097/01.ta.0000209172.75637.db, indexed in Pubmed: 16531854.

39. Vercellino M, Votta B, Condello C, et al. Involvement of the choroid plexus in multiple sclerosis autoimmune inflammation: a neuropathological study. J Neuroimmunol. 2008; 199(1-2): 133-141, doi: 10.1016/j.jneuroim.2008.04.035, indexed in Pubmed: 18539342.

40. Wheelock MJ, Shintani Y, Maeda M, et al. Cadherin switching. J Cell Sci. 2008; 121(Pt 6): 727-735, doi: 10.1242/ jcs.000455, indexed in Pubmed:18322269.

41. Wolburg K, Gerhardt H, Schulz M, et al. Ultrastructural localization of adhesion molecules in the healthy and inflamed choroid plexus of the mouse. Cell Tissue Res. 1999; 296(2): 259-269, indexed in Pubmed: 10382270.

42. Yang J, Dombrowski SM, Deshpande A, et al. VEGF/ NEGFR-2 changes in frontal cortex, choroid plexus, and CSF after chronic obstructive hydrocephalus. J Neurol Sci. 2010; 296(1-2): 39-46, doi: 10.1016/j.jns.2010.06.012, indexed in Pubmed: 20619858. 